\title{
Intimate partner violence: prevalence, contributing factors and spectrum among married couples in Southeast Nigeria
}

\author{
Anolue F. C., Uzoma O. I.* \\ Department of Obstetrics and Gynecology, Imo State University Teaching Hospital, Nigeria \\ Received: 06 July 2017 \\ Accepted: 29 July 2017 \\ *Correspondence: \\ Dr. Uzoma O. I., \\ E-mail: drbiggie2001@gmail.com \\ Copyright: () the author(s), publisher and licensee Medip Academy. This is an open-access article distributed under \\ the terms of the Creative Commons Attribution Non-Commercial License, which permits unrestricted non-commercial \\ use, distribution, and reproduction in any medium, provided the original work is properly cited.
}

\begin{abstract}
Background: Intimate partner violence is a globally acknowledged public health problem. Violence against women is unsurprisingly common albeit under reported in both developing and developed nations. It impacts the physical and mental health of affected women adversely. Even though it appears in different forms it is a malady that deserves increased attention. It is a social menace that is common in Africa with Nigeria being no exception. This study sets out to determine its prevalence, contributing factors and the spectrum of violence against married women in Southeast Nigeria.

Methods: A cross sectional study of prospectively consenting women within a community based setting was done in Orlu, Nigeria during a period between 1st August to 31st August 2016. A total of 695 respondents were initially recruited and given structured questionnaires, of this number 13 failed to answer questions on intimate partner violence and hence were excluded, thus the final study population was actually 682 . Using a $95 \%$ confidence interval, $5 \%$ margin of error, population proportion of 0.5 , the minimum sample size was calculated as 384 using the Cochran's formula for sample size. The data was then analyzed using Statistical Package for Social Sciences (SPSS) version 20.

Results: A total of $682(100 \%)$ respondents met the criteria for the study, of this number $382(56 \%)$ had experienced some form of IPV while $300(44 \%)$ had not. The factor most frequently associated with abusive behavior was financial requests/constraints accounting for 123 cases (32.2\%). Injuries were sustained by 130 women (34\%) with 66 of them suffering miscarriages (17.28\%). Two hundred and twenty four women (32.8\%) had experienced only one form of abuse while $158(23.17 \%)$ reported multiple forms of abuse. Intimate partner violence was most prevalent among women within the 25-34 years age range constituting a total of $170(44.5 \%)$ cases of abuse. Those married women with only primary education were the subset of the study population that had the greatest number of abused women; 138 cases $(38.1 \%)$.

Conclusions: Intimate partner violence is a pervasive problem in Nigeria with a prevalence of $56 \%$ in this study. Various factors particularly financial constraints, incitement, alcoholism and substance abuse were contributing factors in cases of IPV. Intimate partner violence may appear as a single form or as multiple forms of abuse.
\end{abstract}

Keywords: Abuse, Coercion, Depression, Intimate partner violence, Marital rape

\section{INTRODUCTION}

The terms domestic violence (DV) and intimate partner violence (IPV) are frequently used interchangeably in current literature. ${ }^{1}$ It is a global burden with serious public health and social implications. It is a menace that cuts across socioeconomic, religious, cultural and class borders. $^{2}$ It affects both males and females even though this study focuses on its effects on women within the setting of marriage. Various definitions exist for IPV, one 
definition by the World Health Organization (WHO) in its 2010 report defined it as behavior within an intimate relationship that causes physical, sexual or psychological harm, including acts of physical aggression, sexual coercion, psychological abuse and controlling behaviours. $^{3}$

Women of reproductive age are more vulnerable to abuse by intimate partners than by any other perpetrator. ${ }^{4}$ Even pregnant women are victims of IPV, in Africa a strong link between IPV and HIV infection has been shown by different researchers. ${ }^{4-6}$

Violence against women is a term used to collectively refer to violent acts that are primarily or exclusively committed against women. The United Nations General Assembly defines violence against women as any act of gender-based violence that results in, or is likely to result in physical, sexual or mental harm or suffering to women, including threats of such acts, coercion or arbitrary deprivation of liberty, whether occurring in public or in private life. ${ }^{1}$

The World Health Organization multi-country study indicated that worldwide domestic violence against women ranged from $15 \%$ in Japan to the highest level of $71 \%$ in Ethiopia. ${ }^{5}$

Studies done in Africa demonstrate a very high incidence of IPV as highlighted in a systematic review done by Shamu $\mathrm{S}$ et al. ${ }^{6}$ A study in eastern Nigeria showed that $92 \%$ of the victims of IPV were women while only $8 \%$ were men. ${ }^{7}$

Intimate partner violence takes different manifestations and forms, which include: physical abuse (being, kicking, knocking, choking, female genital mutilation, confinement and choking), sexual abuse (marital rape, sexual assault, harassment or exploitation), neglect, spiritual abuse, economic abuse and emotional or psychological abuse. ${ }^{1,2}$

The impact of IPV is far reaching having physical and mental health implications. An extreme consequence which is unfortunately not uncommon is murder. Many women suffer in silence as it is often protected by family secrecy, cultural norms, fear, shame, and the attendant social stigma make many of these affected women remain silent. ${ }^{8}$ Hence a major challenge associated with IPV is the fact that it tends to be under reported and in some settings it is still a culturally acceptable practice.

This study looks at the contributing factors to IPV among married couples, its prevalence and the spectrum of abuse among the study population.

\section{METHODS}

This was a cross sectional study, it used a community based approach during a period between $1^{\text {st }}$ August to $31^{\text {st }}$
August 2016. This a period in the Southeastern part of Nigeria when women from urban centres return to either their hometowns or that of their spouses in mostly semiurban areas to partake in developmental church based activities; it is popularly referred to as the annual August meeting. This window afforded access to both rural and urban respondents. Structured questionnaires were given to prospectively consenting women in churches and within local married women's meetings within Orlu in Southeastern Nigeria. Assistance was granted in carefully explaining aspects of the questionnaires where areas of difficulty were encountered. This was only necessary in 36 cases. Of a total of 695 consenting respondents only 682 qualified for the study, 13 declined to volunteer information on IPV and were duly excluded.

\section{Statistical analysis}

Using a 95\% confidence interval, 5\% margin of error, population proportion of 0.5 , the minimum sample size was calculated as 384 using the Cochran's formula for sample size. The data obtained was then analyzed using SPSS version 20.

\section{RESULTS}

At the start of the study 695 married women where recruited but thirteen of them failed to disclose/discuss issues bordering on intimate partner abuse. These 13 failed to meet the criteria for the study, there was an overall response rate of $98 \%$. This is illustrated in Figure 1.

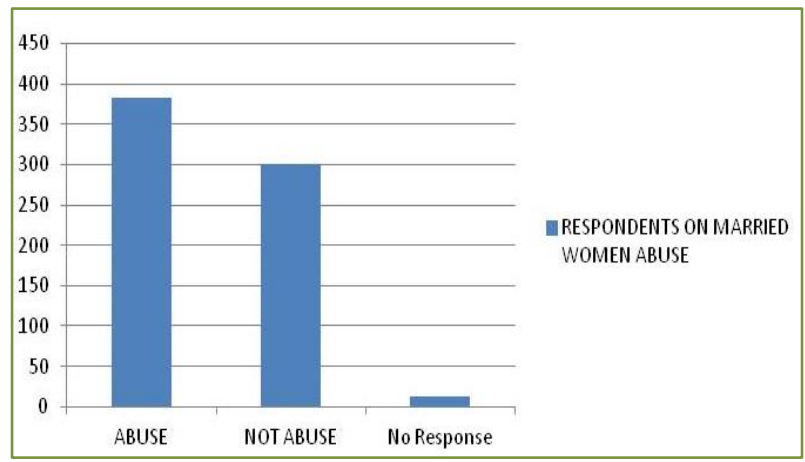

Figure 1: Distribution of respondents who qualified as the study population.

A total of 682 respondents who met the inclusion criteria formed the study population here. Intimate partner violence was encountered by 382 married female respondents $(56 \%)$ within the study population, the remaining $300(44 \%)$ had not experienced IPV. With a prevalence of $56 \%$, the pervasive nature of the problem is clearly defined. The age distribution of the respondents and their husbands spanned from 15 years to 71 years. The largest group of married women were those within the 25-34 years age range constituting 276 respondents (40.5\%). For the husbands, the $35-44$ years age interval 
was the single largest group accounting for 217 men $(31.8 \%)$. This can be seen in Table 1 .

Table 1: Distribution of respondents using age interval.

\begin{tabular}{|lll|}
\hline Age Interval & Female $(\%)$ & Male $(\%)$ \\
\hline $15-24$ & $39(5.72)$ & $1(0.15)$ \\
\hline $25-34$ & $276(40.47)$ & $89(13.05)$ \\
\hline $35-44$ & $210(30.79)$ & $217(31.81)$ \\
\hline $45-54$ & $114(16.72)$ & $206(30.21)$ \\
\hline$\geq 55$ & $43(6.31)$ & $169(24.78)$ \\
\hline Total & 682 & 682 \\
\hline
\end{tabular}

Intimate partner violence was most prevalent among women within the 25-34 years age range constituting a total of $170(44.5 \%)$ cases of abuse. Those married women with only primary education were the most abused subset of the study population; 138 cases $(38.1 \%)$. The age and educational distribution of those who had suffered IPV are illustrated in Tables 2 and 3 respectively. Table 2 focuses on the age distribution only.

Table 2: Distribution by age groups of abused respondents.

\begin{tabular}{|ll|}
\hline Age Interval & Female $(\%)$ \\
\hline $15-24$ & $15(3.93)$ \\
\hline $25-34$ & $170(44.50)$ \\
\hline $35-44$ & $150(39.27)$ \\
\hline $45-54$ & $34(8.90)$ \\
\hline$\geq 55$ & $13(3.40)$ \\
\hline Total & 382 \\
\hline
\end{tabular}

Table 3: Distribution by educational qualification of abused respondents.

\begin{tabular}{|ll|}
\hline Level of Education & Female $(\%)$ \\
\hline None & $33(8.69)$ \\
\hline Primary & $138(36.13)$ \\
\hline Secondary & $122(31.94)$ \\
\hline Tertiary & $89(23.24)$ \\
\hline Total & 382 \\
\hline
\end{tabular}

Of the $56 \%$ who had been abused, the abuse varied from a single form of abuse in 224 women (32.8\%) to multiple forms of violence in 158 respondents (23.2\%). This is illustrated in Table 4.

Table 4: Distribution of respondents by level of abuse/violation.

\begin{tabular}{|ll|}
\hline None & Number $(\%)$ \\
\hline Single & $300(43.99)$ \\
\hline Multiple & $224(32.84)$ \\
\hline Total & $158(23.17)$ \\
\hline
\end{tabular}

Of the 224 victims of a single form of violence, 108 $(48.2 \%)$ said they had been subjected to various forms of verbal derision, $60(26.7 \%)$ were victims of physical violence (beating, flogging, spitting, and having hot water poured on them), 33 individuals $(14.7 \%)$ experienced sexual violence, $16(7.1 \%)$ were temporarily abandoned being sent back to their paternal homes, $5(2.2 \%)$ were victims of financial neglect, $2(1 \%)$ experienced religious abuse.

Table 5: Distribution of respondents by factors contributing to abuse.

\begin{tabular}{|ll|}
\hline Factor $(\mathrm{s})$ & Number of Victims of IPV \\
\hline Substance abuse & $15(3.9 \%)$ \\
\hline Drunkenness & $40(10.5 \%)$ \\
\hline Financial request & $123(32.2 \%)$ \\
\hline Sexual advances & $29(7.6 \%)$ \\
\hline Incitement & $53(13.9 \%)$ \\
\hline Multiple factors & $74(19.4 \%)$ \\
\hline Others & $48(1.6 \%)$ \\
\hline Total & $382(100 \%)$ \\
\hline
\end{tabular}

Different contributing factors for IPV were identified in this study these included financial demands/constraints which was responsible in 123 cases $(32.2 \%)$ of abuse, a combination of factors were implicated in 74 cases (19.4\%), incitement accounted for 53 (13.9\%), alcohol intoxication/ being drunk was the sole factor in 40 cases (10.5\%), spurned sexual advances resulted in 29 women (7.6\%) being abused by their husbands, substance abuse was the least common cause accounting for 15 cases (3.9\%) while other factors contributed to 48 cases (12.6\%). Table 5 highlights these contributing factors.

Injuries were sustained by 130 women (34\%) with 66 of them suffering miscarriages (17.3\%).

The majority of the 682 respondents and their husbands had attained primary school education or higher levels of educational attainment with the women having literacy rates of $95.2 \%$ and the men $93.8 \%$, while the uneducated were in the minority $4.8 \%$ versus $6.2 \%$ for the married women and their husbands respectively.

Table 6: Distribution of respondents by educational qualification.

\begin{tabular}{|lll|}
\hline Level of education & Female $(\%)$ & Male $(\%)$ \\
\hline None & $33(4.84)$ & $42(6.16)$ \\
\hline Primary & $138(20.24)$ & $132(19.36)$ \\
\hline Secondary & $322(47.21)$ & $361(52.93)$ \\
\hline Tertiary & $189(27.71)$ & $147(21.55)$ \\
\hline Total & 682 & 682 \\
\hline
\end{tabular}

Many of the respondents had conflict resolution methods they resorted to when incidents of abuse came up. These are shown in Table 7 . A relative was the most commonly used mediator with 88 respondents $(23 \%)$ relying on this 
option. The majority of respondents kept it to themselves choosing to have no arbitrator when there was an incidence of IPV, they were 100 such cases (26.2\%). Religious personalities (the clergy) were a common staple for conflict management amongst couples having the issue of IPV with 59 respondents (15.5\%) resorting to this avenue for conflict resolution. Others involved in conflict resolution in IPV were traditional rulers, community heads, marriage counsellors, friends and multiple modes (a combination of two or more of the above listed means with only a few engaging law enforcement agencies), these accounted for $3.4 \%$.

Table 7: Distribution of respondents by arbitration/settlement modalities.

\begin{tabular}{|l|l|}
\hline Modalities(s) & Response (\%) \\
\hline None & $100(26.18)$ \\
\hline Relation & $88(23.04)$ \\
\hline Traditional ruler & $13(3.40)$ \\
\hline Community head/kinsmen & $23(6.02)$ \\
\hline Clergy & $59(15.45)$ \\
\hline Marriage counsellors & $17(4.45)$ \\
\hline Friends & $16(14.19)$ \\
\hline Multiple modes & $49(12.83)$ \\
\hline Others & $17(4.45)$ \\
\hline Total & $382(100)$ \\
\hline
\end{tabular}

\section{DISCUSSION}

Violence against women especially by intimate partners is a public health problem with global ramifications. IPV is a reality in both developing and developed nations. ${ }^{9}$ In its 2010 report the World Health Organization defines IPV as behavior within an intimate relationship that causes physical, sexual or psychological harm, including acts of physical aggression, sexual coercion, psychological abuse and controlling behaviors. ${ }^{10}$ The WHO also reports that $15 \%-71 \%$ of women have encountered physical or sexual violence or a combination of the two by a intimate partner. ${ }^{10}$ These estimates fail to factor in women who commit suicide as a means of escaping chronic cases of IPV and those who eventually die homeless having fled from abusive relationships. ${ }^{11,12}$ There is statistical evidence that in the USA between 1,000 to 1,600 women die due to violence unleashed on them by their male partners. A report published in 2000 showed that there were 48 million cases of IPV in the form of physical violence or rape in the USA. ${ }^{1}$

The prevalence in this study mirrored that seen in studies done in eastern India and Pakistan. ${ }^{13,14}$ The overall complexion of this problem assumes different proportions in different countries for instance; Twelve thousand women die every year in Russia as a result of domestic violence. The Human Rights Commission of Pakistan says 80 percent of women there are victims of domestic violence, a much higher prevalence than was seen in this study. The killing of women by their husband's accounts for $50 \%$ of murders in Bangladesh. In South Africa,
49,280 cases of rape were reported in 1998 while Nongovernmental agencies assert that the actual number of rapes is higher since many incidents go unreported. ${ }^{15}, 16,17$

Intimate partner violence cuts across all strata of the society irrespective of age, educational attainment, poverty/affluence, and even religious/non-religious groups are all affected. Traditionally, in Nigeria, as in many other African countries, the beating of wives and children is widely sanctioned as a form of discipline. This sociocultural attitude further fuels this societal blight. ${ }^{17}$, 18

Intimate partner violence can take various forms, according to WHO this includes; ${ }^{3}$

- Acts of physical violence, such as slapping, hitting, kicking and beating.

- Sexual violence, including forced sexual intercourse and other forms of sexual coercion.

- Emotional (psychological) abuse, such as insults, belittling, constant humiliation, intimidation (e.g. destroying things), threats of harm, threats to take away children.

- Controlling behaviours, including isolating a person from family and friends; monitoring their movements; and restricting access to financial resources, employment, education or medical care.

A more elaborate categorization was put forward by Aihie ON (2009) with six major types: ${ }^{18}$

- Physical abuse: here physical force is used in a way that can or might injure the victim. This includes choking, beating, pushing, biting, spitting, kicking, knocking, confinement and female genital mutilation. Physical abuse is one of the most common forms of IPV.

- Economic abuse: This covers stealing from or fraudulent acquisition from a loved one, withholding money for essential things like food and medical treatment, manipulation or exploitation of family members for financial gain.

- Sexual abuse: This includes all forms of sexual assault, exploitation or harassment and marital rape.

- Neglect: Abdication of one's duty to provide food, clothing, shelter, medical care within the family unit.

- Spiritual Abuse: The use of religious or spiritual beliefs to oppress an individual.

- Emotional Abuse: This includes threatening a person or harming a person's sense of self-worth by putting him/her at risk of serious behavioral, cognitive, emotional or mental disorders.

This study showed that emotional abuse (verbal derision) was the most common form of IPV encountered within the study population which agrees with similar findings in a study done in Enugu by Obi and Ozumba (2009) which showed shouting at a partner (emotional abuse) as the most common form of abuse in their study. ${ }^{7}$ Other 
forms of IPV seen in this study were physical violence, marital rape, abandonment (being driven out of the home), food deprivation, pouring hot water on the victim, numerous other forms were mentioned like forced imprisonment, and emotional neglect. Some beatings resulted in hospitalization, miscarriages, and physical injuries. A hospital based study in Nairobi showed sexual violence as being the more common form of IPV with a prevalence of $61.5 \%$ while the proportion of physical assault was $38.5 \%$ with the majority of the perpetrators of gender based violence being married $(72.3 \%)$, alcohol was implicated as a significant contributor in $10.1 \%$ of cases. $^{19}$

The negative impact of IPV on the health of the victim and even on their children has been extensively examined in recent literature. ${ }^{20}$ There is an increasing understanding and recognition that the potential health consequences of IPV both in relation to acute and chronic health issues goes beyond the physical trauma cases that are commonly seen in emergency departments of hospitals. ${ }^{21}$ A growing body of literature has focused on associations between IPV and physical and mental health. ${ }^{22,23}$ Intimate partner violence has been linked to PTSD, anxiety, depression and other related psychological conditions. ${ }^{24}$

In a study done in Rwandan, it was found that women who experienced any type of IPV were more likely to report non-HIV STIs, but women who had specifically experienced sexual and emotional abuse were more likely to test positive for HIV compared to women who had not experienced abuse. ${ }^{25}$ A study done in South Africa (Jewkes et al) there were a higher number of HIV cases reported by women with a history of partner violence (physical or sexual IPV) compared to women who had not been abused and this was statistically significant. This was the case both at baseline and also for the newly acquired cases of HIV observed throughout the study period. $^{26}$

The effects of IPV impact on other areas of family life such as pregnancy loss (which was seen in this study), psychological traumatization of the children, economic consequences and death. ${ }^{1,18}$

Conflict resolution techniques varied amongst couples with some having no arbitrators, while others turned to relatives, traditional rulers, clergymen, friends, and a small number used the police for this. A study in China showed that family intervention, community level interactions and public agencies like the police were the means by which conflict resolution was sought after. ${ }^{27}$

Because the victims of IPV quite often suffer in silence, simply refusing to discuss the problem or downplaying the scope of the problem, it makes obtaining data difficult. This is even more pronounced within the institution of marriage on the African continent where cultural views occasionally rubber stamp the use of violence against women hence making a subset of the abused unwilling to express the more subtle forms of IPV. It is therefore almost impossible to ascertain the entire spectrum of the malady. The issue of men being victims of IPV was not explored in this study

\section{CONCLUSION}

The prevalence of IPV was $56 \%$ in this study. Factors such as alcoholism, substance abuse, and financial constraints were identified as factors contributing to this menace. Given its widespread occurrence and deleterious effects on the victim; it is a public health challenge that deserves far reaching public enlightenment, community engagement and a legislative framework that places emphasis on victim protection.

Funding: No funding sources

Conflict of interest: None declared

Ethical approval: The study was approved by the Institutional Ethics Committee

\section{REFERENCES}

1. Alokan FB. Domestic violence against women; a family menace. 1st Annual International Interdisciplinary Conference, AIIC April, Azores, Portugal; 2013:24-26

2. Babu BV, Kar SK. Domestic violence in Eastern India: Factors associated with victimization and perpetration. Public health. 2010;124:136-148.

3. World Health Organization, Preventing Intimate Partner and Sexual Violence Against Women: Taking Action and Generating Evidence, World Health Organization, Geneva, Switzerland;2010.

4. Fonck K, Els L, Kidula N, Ndinya-Achola J, Temmerman M. Increased Risk of HIV in Women Experiencing Physical Partner Violence in Nairobi, Kenya. AIDS and Behavior. 2005;9:335-9.

5. Moreno CG, Jansen H, Ellsberg M, Heise L, Watts C. WHO multi-country study on women's health and domestic violence against women initial results on prevalence, health outcomes and women's responses. Lancet. 2006;368:1260-1269.

6. Shamu S, Abrahams N, Temmerman M, Musekiwa A, Zarowsky A. A systematic review of African studies on intimate partner violence against pregnant women: prevalence and risk factors. PLoS One. 2011;6(3):17591.

7. Obi SN, Ozumba BC. Factors associated with domestic violence in Southeast Nigeria. J Obstet Gynecol 2007;27:75-78.

8. Michau L, Naker D. Mobilizing Communities to Prevent Domestic Violence: a resource for Organizations in East and Southern Africa;2003

9. WHO. Multi country study on Women's health and domestic violence against women. Geneva: World Health Organization;2007.

10. WHO. Multi-Country study on women's health and domestic violence against women. Summary report of initial results on prevalence, health outcomes and 
women's responses. Geneva, World Health Organization;2005

11. Devries KM, Mak JY, Bacchus LJ, Child JC, Falder $\mathrm{G}$, Petzold $\mathrm{M}$ et al. Intimate partner violence and incident depressive symptoms and suicide attempts: a systematic review of longitudinal studies. PLoS Med. 2013;10(5):e1001439.

12. United States Department of Health and Human Services (2007). Center for Disease control and Prevention (CDC). Intimate Partner Violence: Overview. Available at http://www.cdc.gov.nicpc/ factsheets/ipoverview.htm.

13. Babu BV, Kar SK. Domestic violence against women in eastern India: a population-based study on prevalence and related issues. BMC Public Health 2009;9:129.

14. Ali TS, Asad N, Mogren I, Krantz G. Intimate partner violence in urban Pakistan: prevalence, frequency, and risk factors. International Journal of Women's Health. 2011;3:105-115.

15. Chervyakov VV, Shkolnikov VM, Pridemore WA, McKee M. The changing nature of murder in Russia. Social Sci Med. 2002;55:1713-24.

16. Ali TS, Mogren I, Krantz G. Intimate partner violence and mental health effects: A populationbased study among married women in Karachi, Pakistan. Int J Behavioral Medicine. 2011;20:13139.

17. Adebayo AA. Sociological implications of domestic violence on children's development in Nigeria. Journal of African Studies and Development. 2014;6(1):813.

18. Aihie ON. Prevalence of Domestic Violence in Nigeria: Implication for Counselling. Edo J Couns. 2009;2(1):1-8.

19. Temmermen M, Fonck K, Els L, Kidula N, NdinyaAchola J. Increased risk of HIV in women experiencing physical partner violence in Nairobi, Kenya. AIDS and Behavior. 2005;9(3):335-9.

20. Oladepo O, Yusuf OB, Arulogun OS. Factors Associated with Gender based violence in selected states in Nigeria. Afr J Reprod Health. 2011;15(4):78-86.

21. Luis A, Marinheiro V, Mi VE, Souza L. Prevalence of violence against women users of health care services. Rev Saude Publica. 2006;40(4):1-7.

22. Bonomi AE, Thompson RS, Anderson M, Reid RJ, Carrell D, Dimer JA et al. Intimate partner violence and women's physical, mental, and social functioning. Am J Prevent Medic. 2006;30(6):458466.

23. Wong JYH, Tiwari A., Fong DYT, Humphreys J, Bullock L. Depression among women experiencing intimate partner violence in a Chinese community. Nursing Res. 2011;60(1):58-65.

24. Ishida K, Stupp P, Melian M, Serbanescu F, Goodwin M. Exploring the associations between intimate partner violence and women's mental health: evidence from a population-based study in Paraguay. Social Sci Medic. 2010;71(9):1653-61.

25. Dude AM. Spousal intimate partner violence is associated with HIV and other STIs among married Rwandan women. AIDS Behavior. 2011;15(1):142152.

26. Jewkes RK, Dunkle K, Nduna M, Shai N. Intimate partner violence, relationship power inequity, and incidence of HIV infection in young women in South Africa: a cohort study. Lancet. 2010;376:41-8.

27. Tian-yu GU, Ying-ping YE, Hao Z, Li S. A preliminary study on the current situation and prevention of domestic violence in Hainan. Humanities Soc Sci J Hainan Univ. D923.9;D669.1.

Cite this article as: Anolue FC, Uzoma OI. Intimate partner violence: prevalence, contributing factors and spectrum among married couples in Southeast Nigeria. Int J Reprod Contracept Obstet Gynecol 2017;6:3748-53. 